\title{
The relationship of stressful life events with parent stress and satisfaction with family life among a sample of parents in Irbid city
}

\author{
${ }^{1}$ Abd-almuhdi M. Sawalhah, ${ }^{2}$ Sameer F. Ailabouni, ${ }^{3}$ Wafa M. Alashqar \\ 1,3Professor at Faculty of Educational Sciences, Irbid National University, Jordan \\ ${ }^{2}$ Associate Professor at Faculty of Educational Sciences, Irbid National University, \\ Jordan \\ 22sameerailabouni61@yahoo.com
}


المجلة الدولية للدراسـات التربوية والنفسية

International Journal of Educational \& Psychological Studies (EPS)

Journal Homepage: https://www.refaad.com/views/EPSR/Home.aspx

www.refaad.com

ISSN: 2520-4149 (Online) 2520-4130 (Print)

\title{
The relationship of stressful life events with parent stress and satisfaction with family life among a sample of parents in Irbid city
}

\author{
1Abd-almuhdi M. Sawalhah, 2Sameer F. Ailabouni, 3Wafa M. Alashqar \\ 1,3Professor at Faculty of Educational Sciences, Irbid National University, Jordan \\ ${ }^{2}$ Associate Professor at Faculty of Educational Sciences, Irbid National University, Jordan

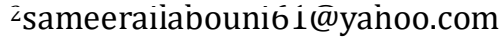

Received: 14/10/2020 Revised: 30/10/2020 Accepted: 30/11/2020 DOI: https://doi.org/10.31559/EPS2021.9.3.14

\begin{abstract}
:
The aim of the present study is to identify the relationship between stressful life events and parental tension, and life satisfaction according to the heterosexual gender, and the economic level. And disclosure of the effect of stressful life events on these two-family variables in a sample of fathers in Irbid. The study sample consisted of (478) fathers and mothers, and the study used the stressful life events scale and the parental tension scale. The results showed a positive statistically significant relationship between stressful life events and parental tension, and that this relationship among fathers is stronger than that of mothers. And the existence of a statistically significant negative relationship between stressful life events and satisfaction with family life, and that this relationship among mothers is stronger than that of fathers. The results also indicated that there were no statistically significant differences in the level of stressful life events and parental tension. While there were statistically significant differences in the level of satisfaction with family life due to the gender variable in favor of mothers. The results also showed a statistically significant difference between the averages of parents' estimates on the two measures of stressful life events and parental stress in favor of the low economic level. While it came in favor of the high economic level of life satisfaction. With regard to stressful life events that predicted parental stress in both sexes, it was found that all dimensions were positive predictors. As for stressful life events that predicted satisfaction with family life for both sexes, it was found that all dimensions were negative predictors.
\end{abstract}

\section{Study Literature}

The family is the basic unit of society, and it is the oldest and most flexible social institution. Despite the importance of the family in society, today it faces many internal challenges at the family level and external at the environmental and social levels. Where stressful events and stress that occur in parents are among the most common problems among householders at the present time, which can affect all areas of their life, including feelings, self-values, and moods. Perhaps stressful life events often linked and lead to some disorders and dissatisfaction in individuals.

Stressful life events, whether negative or positive, are changes that may occur suddenly in the lives of individuals and may have a strong impact on their mental health (Hamman, 2005). Stressful life events were classified according to the degree to which they affect the individual's life or change the way the individual feels in his health or his relationship with others (Allam, 2011).

Exposure to great stress increases when parents face the daily life requirements and what they depend on, which leads to increased pressure on parents and the struggle between work and family (Evenson\& Simon, 2005). Among the factors that influence parents' behavior due to environmental factors that shape their behavior are sources of stress and lack of support (Dabrowska \& Pisula, 2010). 
Stressful events as indicated (Hassanzadeh et al., 2017) have a positive relationship with disorders in general and psychological stress in particular.

In addition, that stressful life events related to the economic and social aspect have an impact on the effectiveness of the individual from the psychological point of view. Individuals exposed to stressful life events are more likely to report psychological problems, as these events are described as separate, measurable circumstances such as job and security disputes, financial problems, social relationships, family and personal conflicts, and health-related stresses, which can have a negative impact on the condition. Psychological (Karademas \& Roussi, 2016).

Maurer \& Smith (2013) defined stressful life events as changes in personal, social, family and professional life that require the individual to adapt and adjust accordingly. Luhman, Lucas, Eld \&Diener (2012) indicates that life satisfaction is affected by positive stressful events such as marriage, having a new child, or getting a better job. On the other hand, life satisfaction is negatively affected by negative events such as divorce, loss of work, illness, and death.

Family natural events such as the death of one of its members, or many emotional experiences, trauma, and financial problems are among the most important causes of parental tension, and very high expectations may be considered one of the main causes (Sori, 2006). Parental tension is defined as a disorder of parent's system stable state, which arises from external or internal factors, or both, and parental tension is seen as a change in the family balance that threatens this system (Salerno, Yang, Nau\& Chai, 2011). It can be defined as any stressful event related to one or more members or the completely family system at a specific time, which affects the emotional relationship between family members, their moods and well-being, as well as on family relationships (Goldenberg \& Goldenberg, 2008).

Parental tension leads to many effects on the interaction and performance of family members, including 1 . Poor communication skills during family discussions and conversations; 2 . wekness, health problems, and Exhaustion; 3. Confusion in relationships with other family members; 4. Individuals tend to adopt undesirable behaviors and depend on them (Gupta \&Venkatesan, 2018). Stress affects most events of family life, so the individual who suffers from parental tension may lead to sensitivity and irritation more than usual, so when the individual in the family suffers from high levels of stress, he will feel tired and exhausted. The constant preoccupation of family members, lack of relaxation, in addition to not spending a long time with some of the things that lead to feelings of frustration for many of them, and thus the emergence of negative effects on the extent of the functional performance of the family (Kellermanns\& Hoy, 2017).

Economically disadvantaged families may be particularly vulnerable to the negative psychological impact of exposure to stress, because they experience higher rates of stress and have fewer resources to deal with (Sheidow et al., 2001). The quality of family relationships and solidarity and cohesion, and parenting practices are directly related to the mental health of family members, and among the sources of parental tension are the following:

- Marital Dissatisfaction: Dissatisfaction can be a source of stress for parents, affecting daily interactions and relationships. Parents who are dissatisfied with their marital relationships are more vulnerable to negative influence and less able to be emotionally available to their children. And that the quality of marital relations and the interaction of parents with children appears more among mothers through the emergence of negative effects resulting from marital distress for their interactions with children (Parke, 2002).

- Family chaos: The perceptions of family environment is a chaotic organization that can also add to the parents and some sort of stress, and these perceptions differ between partners within the same house because of individual differences in the degree of tolerance, disorganization, and a lack of routine. Since high levels of family chaos predict low levels of supportive responses, and that the relationship between the perceptions of chaos at home and the parents in response to the negative feelings of their children to be stronger for mothers than fathers (Valiente, Lemery-Chalfant\&Reiser, 2007).

- Depressive characteristic: When parents experience fatigue, loss of interest, and a general negative mood, they are likely to be less responsive to the family, and that it is related to parents' unsupportive responses to negative children's feelings. Parental tension is negatively related to the lack of communication between the father and the son, and that the communication between the son and the father who is not repressed is more positive in the home (Lovejoy, Graczyk, O'Hare \&Neuman, 2000).

- Dissatisfaction job role: stress has been associated with the job role of the individual, and his interactions at work, which leads to the interference of work pressures in family life, especially the high employment pressure of parents, which negatively affects their communication with the husband and children (Glendon, Clarke \&Mckenna, 2006).

Within the family, there are many factors that may contribute to this, such as objective factors related to the father, such as the lack of balance between work and family; Or factors related to children, such as abnormal behaviors; Or subjective parenting factors such as unstable emotional experiences with a wife or children (Mendenhall \& Mount, 2011). Parents may suffer from great stress as a result of reduced personal or family 
relationships, financial stress, lack of ability to work, self-care, and a weak ability to practice parenting methods when there are health conditions affecting a family member (Nadkarni\&Fristad, 2012).

Widarsson et al. (2012) indicate that mothers' stress is higher during inactivity, role restriction, marital problems, and health problems, and that working mothers face more stress associated with daily demands and repeated frustrations. Whereas parents, stress is highest during social isolation, work and the economic aspect. Effective and consistent measurement of the family outcome variable is essential and provides the necessary framework for identifying relevant individual and family behavioral factors that can mitigate or mediate negative daily influences. On adaptation, communication, and overall family functioning (Poff, Zabriskie\& Townsend, 2010).

Social adjustment factors, good mental health, and positive attitudes towards the family are among the most important indicators of satisfaction with family life. In addition to satisfaction with social life, self-efficacy, and family entertainment (Bloom \& Smith, 2001). The importance of studying family satisfaction derives from the need to understand the ways in which feelings and attitudes towards the individual's family arise in both families' jobs and dysfunction (Peterson \& Bush, 2013).

Zabriskie \& Ward (2013) indicate that levels of satisfaction with family life differ from one family to another, and that satisfaction with positive family life is associated with a healthy psychological aspect. Rahim, Ishak, Shafia\&Shafiai (2013) indicate that performance in the family, family resilience, and spending time with the family have a great and direct impact on satisfaction with family life, except for parental participation, which has no effect.

Family interaction is considered one of the most important influences on the quality of family jobs, it differs according to job performance and the level of family satisfaction, and family beliefs have a great impact on the quality of family performance and satisfaction with their family life.

In addition, that the higher perceived effectiveness of the family is accompanied by an increase in the level of satisfaction with the family. The effectiveness of fathers and sons was linked to family satisfaction, and the effectiveness of the family contributed to satisfying parents with their family life, either directly or through its impact on the quality of family function (Bandura, Caprara, Barbaranelli, Regalia \&Scabini, 2011).

Daradkeh (2019) conducted a study aimed at investigating the meaning of life and happiness as predictors of satisfaction with family life among a sample of married people in northern Jordan, and the study sample consisted of (918) husbands and wives. The results showed an average level of both satisfaction with family life and meaning of life, and happiness. And the existence of differences between the sexes on the two scales of satisfaction with family life and the meaning of life in favor of males, and the existence of a statistically significant positive relationship between satisfaction with family life and both the meaning of life and happiness, and that this relationship among females is stronger than it is for males.

The study (Flouri, Narayanan \&Naerde, 2018) aimed to find out the role of stressful life events in a sample of parents in Norway, where the study sample consisted of (1138) families. The results showed that there was no statistically significant difference between the sexes in stressful life events, and that the number of events predicted the level of mental health similarly to parents. Likewise, personality traits did not affect the relationship of stressful events to mental health symptoms in parents.

As for the study (Chi \& Xu, 2018), which aimed to find out the factors related to parents and their effect on parental tension in Macao, China, the study sample consisted of (251) parents. The results of the study showed that mothers are more stressed than male fathers, and that parental stress is associated with low economic status, while higher income they have less stress. And that self-efficacy reduces parental tension.

In the study (Botha, Booysen \& Wouters, 2018), which aimed to find out the role of socio-economic status in satisfaction with family life in South Africa, the sample of the study consisted of (1794) families. The results of the study showed that high levels of socio-economic status were associated with increased satisfaction with family life, and with the family tool in terms of family resilience.

Ziada (2018) conducted a study aimed at identifying the extent of satisfaction with family life and selfsatisfaction among a sample of Syrian refugees in Jordan in light of some variables, and the study sample consisted of (427) refugees. The results showed an average level of the study sample members in satisfaction with family life and self-satisfaction, and the presence of statistically significant differences in the two scales: satisfaction with family life and self-satisfaction according to gender and in favor of females. The results showed that there are differences in the level of satisfaction with family life due to the age variable and in favor of age (less than 15 years), and the results showed differences in the level of self-satisfaction due to the age variable and in favor of age (16-30 years, 31-45 years).

Chukwuorji, Nwoke\&Ebere (2017) conducted a study aimed at finding out the relationship of stressful life events to family support in a sample of parents in Nigeria, and the study sample consisted of (453) parents. The results showed a negative relationship between stressful life events represented in the health and personal aspect, work / money and advancing age. Family support positively correlated with advanced age. 
Parks, Sweeting \& Wight (2015) conducted a study aimed at finding out the level of parental tension between mothers with high and low education and the support provided to them in Scotland, and the study sample consisted of (5865) mothers. The results of the study showed that parental stress is greater among mothers with higher and lower education, and that the level of support is only 50\%. Tension is higher in parenting, less support, and tension in honest relationships.

As for the study of Bani Mustafa, Al-Sharifin and Tashtoush (2014), it aimed to find out the relationship between stressful life events and the feeling of satisfaction with life in the city of Irbid. The study sample consisted of (350) adults and adults.

The results of the study showed that the level of stressful life events in the study sample was high, while the level of life satisfaction was low, and there was a statistically significant correlation between stressful life events and the feeling of life satisfaction, and the absence of differences in the level of stressful life events and the feeling of satisfaction with life. Attributed to a variable of sex.

(Nelson, O'Brien, Blankson, Calkins \& Keane, 2009) conducted a study that aimed to find out the relationship between family tension with satisfaction and social and emotional practices in America. The sample of the study consisted of (101) father and mother. The results of the study showed that family stress is related to the parents' supportive and non-supportive responses, and that this relationship differs according to the sex of the parents.

The study (Agate, Zabriskie, Agate \&Poff, 2009) aimed to find out the relationship between family leisure and family life satisfaction in America, and the study sample consisted of (898) families. The results of the study showed a positive relationship between family entertainment and family life satisfaction, and that divorce and the age of parents are negative predictors of satisfaction with family life, while high monthly income and stable marital status were positive predictors.

The study aims to know the relationship of stressful life events to parental tension and satisfaction with family life among a sample of fathers in the city of Irbid in light of some variables. By reviewing previous studies, we find that these studies aimed to find out the role of Stressful life events with mental health, family support, or adult feeling of satisfaction, and what distinguishes this study from other previous studies is that it aimed to know the relationship of stressful life events to parental tension and family life satisfaction with a sample of parents in the city of Irbid in light of some variables - and according Researchers' knowledge

\section{Study Problem and Questions}

Individuals go through a set of life experiences or events that may lead to changes in their lives that require varying degrees of adaptation. Transitions and change are inherently stressful, the effect can be positive or negative, and sources of stress may be voluntary or unwanted, clear or ambiguous, predictable or unpredictable all affect the individual. Recently, some situations have emerged that raise and increase the burdens on the Jordanian family, which affect their lives, especially those who are married to them, and from these situations the social roles of the spouses have multiplied, and the material burdens are exacerbated, and the problems of husbands have been exacerbated by the increase of these pressures on them. These various pressures make them anxious individuals, easily provoking their emotions, and making them individuals unable to manage and confront them. This reflected in their performance within the family and the way they interact with others, and states of anxiety, stress and stress have effects that affect the individual's beliefs and self-efficacy.

The patriarchal system considered a temporary valve against the threats it exposed to from various factors, whether environmental, family, social, and others. Parents who do not receive social support may be weak and do not have a strong psychological structure, and their personal inclination may be a reason for that. Hence, parents who suffer from negative events may lack the emotional side to maintain positive relationships with themselves first and with those around them second.

Within the limits of access to Arab databases hence, through this study, the researcher tries to know the relationship of stressful life events to both parental tension and satisfaction with the family life of fathers in light of some variables. Specifically, the study sought to answer the following questions:

1. Is there a statistically significant relationship between the level of stressful life events and between parental stress and satisfaction with family life for the study sample?

2. Does the level of stressful life events differ for the study sample according to gender and economic level?

3. Does the level of parental stress differ among the study sample according to gender and economic level?

4. Does the study sample's level of satisfaction with family life differ according to gender and economic level?

5. What is the proportion of the explained variance that is explained by the stressful life events of parental tension among the study sample members?

6. What is the percentage of the explained variance that is explained by stressful life events with satisfaction with family life among the study sample? 


\section{Objectives of the Study}

The current study aimed to:

- Disclosure of differences in the level of stressful life events, parental tension, and satisfaction with family life among a sample of fathers in the city of Irbid, according to the variables of sex and economic level.

- Identify the relationship between stressful life events and parental tension, and satisfaction with family life among a sample of parents in the city of Irbid.

- Examination of the effect of stressful life events with parental tension, and satisfaction with family life among a sample of fathers in the city of Irbid.

\section{Importance of the Study}

The importance of the theoretical study comes as a cognitive addition to theoretical literature regarding family and scientific life events, and the study provides workers in the field of family counseling and treatment with more information regarding family life satisfaction and its role in facing stress and pressures and alleviating the problems facing the family. The study tries to highlight the role of stressful life events in the ability to stress and satisfaction with family life in light of the variable of sex and economic level and the consequent difference in the predictive value of stressful life events and satisfaction with the family life of parents.

As for the practical aspect, it is important for family awareness and treatment programs, and for those working in the field of family reform in Sharia courts because of their importance and effective role in mitigating the severity of divorce and minimizing the consequences thereof, and through this study, counseling and training programs can be applied in the development of limiting the effects of life. Stress and tension, and programs to develop satisfaction with family life, and design courses for those intending to marry. And that the study will provide measurement tools that can be used by counselors, psychotherapists, families, or institutions concerned with the family, and used in future studies related to these variables.

\section{Conceptual and Procedural Definitions}

- Stressful life events: It is the exposure of the individual to a set of problems and events that cause him to confuse his internal balance as a result of his feeling of threat, and it forces him to make an additional effort to return to his natural balance (Mazloum, 2008). The compressor used in the current study.

- Parental tension: It is one of the types of tension that arises as a result of the superiority and stress of different life requirements on the ability of parents to fulfill personal and family needs (Abidin, 1995). It is procedurally defined by the degree to which the respondent obtains on the parental tension scale used in the current study.

- Satisfaction with family life: is the individual's obtaining of family happiness and satisfaction resulting from the cohesion of individuals in it and the flexibility of communication among its members (Zabriskie \& Ward, 2013), and it is procedurally defined by the degree that the respondent obtains on the measure of satisfaction with family life used in the current study.

\section{Study Limitations}

The scope of application of the current study is determined by the following:

- Temporal limits: The study was implemented during September of 2019.

- Spatial limits: The application of measures was limited to a sample from the city of Irbid in Jordan.

- Human limitations: The sample was restricted to fathers and mothers in Irbid city only.

- Objective limitations: The objective boundaries of the study are confined, which is the stressful life events and their relationship to parental tension and family satisfaction with parents in the city of Irbid in light of some variables.

- Application limits: The application limits are limited to studying through the Internet, and the application was not direct face to face.

\section{Study Variables}

\section{Independent variables:}

Gender: It has two categories (fathers and mothers).

The economic level: it has three levels (low, medium, and high).

Dependent variables:

Stressful life events, parental tension, satisfaction with family life. 


\section{Method and Procedures}

\section{Study Approach:}

The current study followed the relational and comparative descriptive approach, as it examined the level of stressful life events and family tension, satisfaction with family life, and the relationship between them among a sample of fathers in the city of Irbid in light of the variables of sex and economic level.

\section{Study Population:}

The study population consists of all fathers and mothers in the city of Irbid, northern Jordan, and their total number is (792.71) father and mother.

\section{The study sample:}

The sample of the study consisted of (478) participants (239 father and 239 mothers), Selecting the respondents from among the most stressed and stressed parents and the sample was chosen by the intentional method, and Table (1) shows that.

Table (1): The study sample according to the study variables

\begin{tabular}{cccc}
\hline Variables & Categories & Repetition & percentage \\
\hline \multirow{2}{*}{ Sex } & father & 239 & $\% 50$ \\
& mothers & 239 & $\% 50$ \\
& total & 478 & $\% 34.9$ \\
\hline Economic level & low & 100 & $\% 41.4$ \\
& medium & 167 & $\% 23.7$ \\
\hline
\end{tabular}

\section{Study tools:}

\section{First: stressful life events scale:}

The researchers referred to literature and previous studies related to stressful life events, such as the study of Bani Mustafa and others (2014), and the study of Abu Mustafa and Al-Samiri (2008), (Malhotra\& Mehta, 2008), and (Hobson, et al., 1998). The researchers used the scale in the study of Abu Mustafa and Al-Samiri (2008), which consists of (70) paragraph distributed on seven dimensions related to stressful life events: family, economic, academic, social, health, psychological, and political.

Implications of validity scale:

Abu Mustafa and Al-Samiri (2008) verified the validity of the content of the scale by presenting it to (10) faculty members of the faculty of the Department of Mental Health at Ain Shams University.

Asked to review the stressful life events scale and make observations about the scale in terms of the suitability of the paragraphs to the target group and their affiliation with the dimensions Clarity of meaning, and any other appropriate observations. The scale paragraphs and dimensions were agreed upon, as the scale paragraphs remained as they are. The validity of the construction of the scale was also verified by applying it to an exploratory sample of (50) From parents from outside the study sample, and the correlation coefficients for the dimensions were as follows: household (0.40-0.70), economic (0.36-0.72), and academic (0.34-0.61) ), Social (0.35-0.61), health (0.40-0.75), psychological (0.36-0.71), and political (0.52-0.77).

As for the current study, the two researchers verified the indications of the validity of the content by presenting the scale in its original form to a group of (8) arbitrators specialized in education and psychology at Irbid National University, to ensure the suitability of the scale paragraphs for this category of parents to which they will be applied.

The study, where it was unanimously agreed to delete the two dimensions (academic and political) from the scale, with modifications of some paragraphs to suit the parents in Jordan, and the arbitrators unanimously agreed on the paragraphs by (80\%), and this percentage can be relied upon to conduct the study from within its community; Consequently, the scale in its final form consists of (50) items.

The researchers also extracted the construct validity of the scale by applying it to an exploratory sample consisting of (54) fathers and mothers from outside the study sample and from within the study population, then calculated the values of the correlation coefficients for the paragraphs with each dimension, and the values of the correlation coefficients for the paragraphs with the scale as a whole.

Whereas, the values of the correlation coefficients of the paragraphs of the dimension of family events ranged between (0.46-0.83), and the values of the correlation coefficients of the paragraphs of the dimension of economic events ranged between (0.48-0.84), and the dimension of social events ranged between the values of the 
paragraphs correlation coefficients between (0.47-0.85), and in the dimension of Health events, the values of the vertebrae correlation coefficients ranged between (0.49-0.81), and finally the dimension of psychological events, so the values of the vertebrae correlation coefficients ranged between (0.47-0.80), all of which are statistically significant values. The researchers adopted a criterion for accepting the paragraph, that its correlation coefficient for the dimension and the list as a whole is not less than (0.20). (Odeh, 2010).

\section{Stability Indications of the of scale:}

Abu Mustafa and Al-Sumairi (2008) verified the stability of the scale in two ways: The first was by applying it to a survey sample of (50) male and female students. The internal consistency coefficient was calculated for the Cronbach alpha of the dimensions, where these values ranged between (0.78-0.95) and the tool as a whole reached (0.94), and the second method, stability, was applied to the same sample, and it was re-applied two weeks after the first application, and these values ranged between (0.85-0.95), and the tool as a whole reached (0.88).

As for the current study, it verifies the indications of the stability of the scale in two ways: The first is by applying it to an exploratory sample of (54) father and mother from outside the study sample and from within the study population, and the internal consistency coefficient was calculated by the Cronbach alpha method for the dimensions, where these values ranged between (0.73 - 0.86) and the tool as a whole reached (0.92),

Second method was stability stabilization by applying it to the same pilot sample, and it was re-applied two weeks after the first application and according to the Pearson correlation coefficient for them, and these values ranged between (0.81-0.91), and the tool as a whole reached (0.87). The researchers believe that these values are suitable for using the list for the purposes of the current study.

\section{Scale correction:}

The scale consists of (50) paragraphs, consisting of a five-point scale, which is (5 = it applies to me very much, $4=$ applies to me to a large extent, $3=$ applies to me to a moderate degree, $2=$ applies to me to a small degree, 1 = applies to me to a very small degree), All of which are negative paragraphs, and the scores on the overall scale range between (50-250), and this means that the higher the score, the more stressful life events for parents. In order to judge the levels of stressful life events, these grades were converted so that they are confined to (1-5) degrees, and the level of stressful life events was divided into categories according to the following criteria: from (2.33-1) low level, and from (3.67-2.34) medium level and from (5-3.68) a high level (sauro\&lewis, 2012).

\section{Second: parental tension scale:}

The two researchers referred to literature and previous studies related to parental tension, such as the study of Abd al-Rahman and Aladdin (2011), and the study of Al-Layl and Al-Andijani (2015), (Pontoppidan, Nielsen, \&Kristensen, 2018), and (Berry \& Jones, 1995). It is best to use the scale used in the study of Abdul-Rahman and Ala Al-Din (2011), which consists of (40) items distributed on four dimensions related to parents: physiological, cognitive, psychological and social support.

\section{Indication of validity scale:}

Abdul-Rahman and Ala Al-Din (2011) verified the indications of the content validity of the scale by presenting it to (10) arbitrators in psychological counseling and educational psychology in Jordanian universities. He clarified the meaning, and any other appropriate observations. The scale paragraphs and its dimensions were agreed upon at a rate of (75\%), as some of the scale paragraphs were amended.

As for the current study, the two researchers verified the validity of the content by presenting the scale in its original form to a group of (8) arbitrators with specialization in education and psychology at Irbid National University, to ensure the suitability of the scale paragraphs for this category of parents to which the study will be applied.

The arbitrators agreed on the paragraphs at a rate of (80\%), and this percentage can be relied upon to conduct the study. Thus, the scale in its final form consists of (40) paragraphs.

The researchers extracted the construct validity of the scale by applying it to an exploratory sample consisting of (54) fathers and mothers from outside the study sample and within the study population, then calculated the values of the correlation coefficients for the paragraphs with each dimension, values of the correlation coefficients for the paragraphs with the scale as a whole.

Whereas, the values of the correlation coefficients for the paragraphs of the physiological dimension ranged between (0.55-0.80), and the values of the correlation coefficients for the paragraphs of the cognitive dimension ranged between (0.49-0.83).

While the psychological dimension ranged between the values of the correlation coefficients for the paragraphs between (0.51-0.75), and in the social support dimension they ranged from the values of the paragraph correlation coefficients are between (0.48-0.84), all of which are statistically significant values. The researchers adopted a criterion for accepting the paragraph, that its correlation coefficient with the dimension and the list as a whole should not be less than (0.20). (Odeh, 2010). 


\section{Scale reliability:}

Alaeddin and Abdul Rahman (2011) verified the stability of the scale in two ways: the first is by applying it to a survey sample of (30) um, and the internal consistency coefficient was calculated for the Cronbach alpha of the dimensions, where these values ranged between (0.84-0.89) and the tool as a whole reached (0.84)),

Second method: stability by applying it to the same sample, and it was re-applied two weeks after the first application, and these values ranged between (0.52-0.82), and the tool as a whole reached (0.79).

As for the current study, the two researchers verified the indications of the stability of the scale in two ways:

First: applying it to an exploratory sample from outside the sample and from within the study population amounting to (54) father and mother, and internal consistency coefficient of Cronbach alpha was calculated for the dimensions, where these values ranged between (0.73- 0.80) and the tool as a whole reached (0.86).

Second: stability stabilization by applying it to the same pilot sample, and it was re-applied two weeks after the first application. The researchers believe that these values are suitable for using the list for the purposes of the current study.

\section{Scale correction}

The scale consists of (40) paragraphs, consisting of a five-point scale, which is ( $5=$ applies to me very much, $4=$ applies to me to a large degree, $3=$ applies to me to a moderate degree, $2=$ applies to me to a small degree, 1 $=$ never applies) in case of the negative paragraphs, while the positive paragraphs are $(7,15,16,17,31,34,35,36$, $37,39)$, scores on the overall scale range between (50-200), and this means that the higher the score, the higher the score. This is an indication of increased stress in parents. In order to judge the levels of parental stress, the parental tension level was divided into categories according to the following criteria: from (2.33-1) low level, from (3.67-2.34) medium level, and (5-3.68) high level (sauro\&lewis, 2012).

\section{Third: The scale of satisfaction with family life:}

The two researchers referred to the literature and previous studies related to satisfaction with family life, such as the increase study (2018), the Dradak study (2019), (Schnettler et al., 2017), and (Zabriskie \& Ward, 2013), and the researchers considered that it is better to use the scale used in the increase study (2018), consisting of (16) items.

\section{Implications of validity scale:}

Ziada (2018) verified the validity of the content of the scale by presenting it to (8) arbitrators in education and psychology at the Irbid National University, where he requested to view the scale of satisfaction with family life and to observe about the scale.

In terms of the relevance of the paragraphs to the target group and their belonging to the dimensions, and the meaning was clarified and any other appropriate remarks, and the scale paragraphs and its dimensions were agreed upon at a rate of $(80 \%)$, as some of the scale paragraphs were amended. The researcher also extracted the validity of the construction of the scale by applying it to an exploratory sample consisting of (62) fathers and mothers from outside the study sample, and the values of the correlation coefficients for the paragraphs ranged between (0.47-0.77).

As for the current study, the two researchers verified the indications of the validity of the content by presenting the scale in its original form to a group of (8) arbitrators with specialization in education and psychology at Irbid National University, to ensure the suitability of the scale paragraphs for this category of parents to which they will be applied.

The study, and the arbitrators agreed on the paragraphs at a rate of (80\%), and this percentage relied upon to conduct the study. Thus, the scale in its final form consists of (16) paragraphs. The two researchers also extracted the validity of the construction for the scale by applying it to an exploratory sample consisting of (54) fathers and mothers from outside the study sample and within the study population, and then calculated the values of the correlation coefficients for the paragraphs with the scale as a whole. As the values of the paragraph, correlation coefficients for the scale ranged between (0.49-0.83), and all of them are statistically significant values. The researchers adopted a criterion for accepting the paragraph, that its correlation coefficient with the dimension and the list as a whole should not be less than (0.20). (Odeh, 2010).

\section{Procedures:}

To achieve the objectives of the study, the study tools were prepared in their final form after verifying their validity and reliability indicators, after which the scale were distributed to parents in the city of Irbid in September of 2019, through an electronic questionnaire on Google Drive. The respondents took 10 days to answer them, and they were assured that their participation is voluntary, and that the data they will provide will be treated with complete confidentiality and will be used for scientific research purposes. After conducting the exploratory study, it became clear that the time taken by the survey sample members in their responses to the scale ranged between (30-45) minutes, and the answers were uploaded from the site to the SPSS program, then the appropriate statistical treatments were used according to the (SPSS) program to answer the study questions. 


\section{Data analysis:}

In this study, the Pearson correlation coefficient was used to find out the relationship between stressful life events and parental tension, and satisfaction with family life. Arithmetic averages and standard deviations also extracted, and a two-way ANOVA analysis used to determine differences in gender and economic level. Scheffe's test was used for dimensional comparisons. Multiple regression analysis has also been used to reveal the contribution of stressful life events.

\section{Results}

Below is a presentation of the results related to each of the questions that the study tried to answer?

The first question: Is there a statistically significant relationship between the level of stressful life events and between parental stress and satisfaction with family life for the study sample?

To answer this question, Pearson correlation coefficients were calculated between the scores of the sample members on each stressful life event scale, and their scores on the two scale of parental stress and satisfaction with family life, and Table (2) shows that.

Table (2): Correlation coefficients between the scores of the sample members on scale of stressful life events and their scores on the measures of parental stress and satisfaction with family life

\begin{tabular}{ccccc}
\hline Scales & $\begin{array}{c}\text { The total } \\
\text { sample }\end{array}$ & fathers & mothers & Z value \\
\hline Parental stress & $0.47^{* *}$ & $0.49^{* *}$ & $0.44^{* *}$ & $3.84^{*}$ \\
Satisfaction with family life & $-0.46^{* *}$ & $-0.41^{* *}$ & $-0.50^{* *}$ & $3.39^{* *}$ \\
\hline
\end{tabular}

Table (2) shows that there is a positive statistically significant relationship between stressful life events and parental tension, and that this relationship among fathers is stronger than that of mothers. That there is a negative statistically significant relationship between stressful life events and satisfaction with family life, and that this relationship among mothers is stronger than that of fathers.

The results of the study showed that there is a positive relationship between stressful life events and parental tension, and the researchers attribute this result to the events and pressures of life and the burdens on parents that exceed their energies, such as the pressures in family roles that arise from the demands of roles such as parent, husband, employee and other roles. In addition, pressures related to the work environment such as increased job burdens, dissatisfaction with job performance, and others. In addition to pressures related to economic events, such as the accumulation of debts, low wages that are not sufficient for the basic needs of the home, and others. These include pressures related to the loss of a family member, which leads parents to fall prey to stress, anxiety and distraction from basic matters. In recent times, many families, social, and economic events have emerged that raise and increase the burdens on the Jordanian family Who lives in the Irbid region, which have a negative impact on their lives, especially their fathers. The increasing pressures on them have exacerbated parents' problems. These different pressures make them tense individuals, easily provoking their emotions, and making them individuals unable to manage and confront them. In addition, situations of anxiety, stress and stress have effects that reflected in their performance within the family and the way they interact with others.

The results also showed a negative relationship between stressful life events and satisfaction with family life, and the researchers attribute this result to the stresses surrounding fathers in the Jordanian society Who lives in the Irbid region led to a weak level of communication and interaction between family members, in addition to the failure of one or both parents to bear family responsibility for their actions. In addition, duties that supposed to performed, and the ineffectiveness of fathers within the family and the distancing of each of them from their roles, and their unhealthy relationship with children increases the family's sense of insecurity and dissatisfaction with their family life. The incompatibility of the family's economic and social conditions with the standards and expectations of parents and the high level of life difficulties that hinder families in Jordan create in them a lack of acceptance of the satisfaction of these fathers. This leads to fluctuations in feelings of love, happiness and warmth, and lack of concern for family members leads to dispersal and the failure to achieve the true meaning of the family, as dissatisfaction with family life increases the contradictions and the failure to reach the expected goals. Weak family and social ties for family members make them safe and hate. The results of this study are consistent with the study of Bani Mustafa and others (2014), which indicated the existence of a correlation between stressful life events and the feeling of satisfaction with life.

\section{The second question: Does the level of stressful life events differ for the study sample according to gender and economic level?}

To answer this question, arithmetic averages and standard deviations of stressful life events according to the variables of sex and economic level were extracted. 
Table (3): Results of the analysis of binary variance of stressful life events according to the variables of sex and economic level

\begin{tabular}{cccccc}
\hline Source of variation & squares Sum & freedom Degrees & squares Average & P value & $\begin{array}{c}\text { Statistical } \\
\text { significance }\end{array}$ \\
\hline Sex & 0.101 & 1 & 0.101 & 0.017 & 0.843 \\
Economic level & 0.897 & 2 & 0.449 & 0.986 & 0.000 \\
Error & 91.212 & 474 & 0.192 & \\
\hline total & 92.210 & 477 & & \\
\hline
\end{tabular}

It is evident from Table (3) that there are no statistically significant differences in the level of stressful life events due to the gender variable. The table shows that there are statistically significant differences at the level of statistical significance $(\alpha \leq 0.05)$ in the averages of the parents 'estimates on the stressful life events scale, and to know the statistical significance of these differences, Scheffe's test was used for the dimensional comparisons, and Table (4) shows that.

Table (4): Scheffe test results for dimensional comparisons of averages of parents' estimates on the stressful life events scale attributable to an economic level variable

\begin{tabular}{cccccc}
\hline Scale & Economic level & SMA & Low & medium & High \\
\cline { 3 - 6 } & & & 3.81 & 3.47 & 3.59 \\
\hline Stressful life & Low & 3.81 & & 0.17 & $* 0.46$ \\
events & medium & 3.47 & & & 0.09 \\
& High & 3.59 & & & \\
& & & & & \\
\hline
\end{tabular}

* Statistically significant at the level of significance $(\alpha \leq 0.05)$

Table (4) shows that there is a statistically significant difference at the level of significance $(\alpha \leq 0.05)$ between the mean estimates of parents on the scale of stressful life events between those with a low economic level on the one hand and a high on the other in favor of the low economic level.

\section{The third question: Does the level of parental stress differ among the study sample according to gender and} economic level?

To answer this question, the arithmetic averages and standard deviations of parental stress were extracted and Table (5) illustrates this.

Table (5): Results of the analysis of binary variance of parental stress according to the heights of sex and economic level

\begin{tabular}{cccccc}
\hline Source of variation & squares Sum & $\begin{array}{c}\text { freedom } \\
\text { Degrees }\end{array}$ & squares Average & P value & $\begin{array}{c}\text { Statistical } \\
\text { significance }\end{array}$ \\
\hline Sex & 0.214 & 1 & 0.214 & 0.112 & 0.973 \\
Economic level & 1.245 & 2 & 0.623 & 0.000 \\
Error & 99.240 & 474 & 0.209 & \\
total & 100.699 & 477 & &
\end{tabular}

It is clear from Table (5) that there are no statistically significant differences in the level of parental stress due to the gender variable. While it shows that there are statistically significant differences at the level of statistical significance $(\alpha \leq 0.05)$ in the averages of the parents 'estimates on the parental tension scale, and to know the statistical significance of these differences, Scheffe's test was used for the dimensional comparisons, and Table (6) shows that.

Table (6): Scheffe test results for dimensional comparisons of averages of parents' estimates on parental tension scale attributable to an economic level variable

\begin{tabular}{cccccc}
\hline Scale & Economic level & & Low & medium & high \\
\cline { 3 - 5 } & & SMA & 3.77 & 3.63 & 3.67 \\
\hline Stressful life & Low & 3.77 & & $* 0.54$ & 0.16 \\
events & medium & 3.63 & & 0.07 \\
& high & 3.67 & & & \\
\hline
\end{tabular}

* Statistically significant at the level of significance ( $\alpha \leq 0.05)$

Table (6) shows that there is a statistically significant difference at the level of significance $(\alpha \leq 0.05)$ between the mean estimates of parents on the parental tension scale between those with a low economic level on the one hand and the average on the other hand in favor of the low economic level. 
The fourth question: Does the level of satisfaction with family life of the study sample differ according to gender and economic level?

To answer this question, the arithmetic means and standard deviations of parental tension, and Table (7) show this. and to find out whether these apparent differences are statistically significant, an analysis of bilateral variance was used, and Table (7) illustrates this.

Table (7): results of the binary variance analysis of satisfaction with family life according to the variables of sex and economic level

\begin{tabular}{cccccc}
\hline Source of variation & squares Sum & $\begin{array}{c}\text { freedom } \\
\text { Degrees }\end{array}$ & squares Average & P value & $\begin{array}{c}\text { Statistical } \\
\text { significance }\end{array}$ \\
\hline Sex & 0.798 & 1 & 0.798 & 0.847 & 0.000 \\
Economic level & 1.369 & 2 & 0.685 & 0.992 & 0.000 \\
Error & 97.597 & 474 & 0.206 & & \\
total & 99.764 & 477 & & & \\
\hline
\end{tabular}

Table (7) shows that there are statistically significant differences in the level of satisfaction with family life due to the variable of sex, as it is clear from Table (9) that the average of mothers is higher than the average of fathers. Table (10) shows that there are statistically significant differences at the level of statistical significance ( $\alpha$ $\leq 0.05$ ) in the averages of parents 'estimates on the scale of satisfaction with family life, and to know the statistical significance of these differences, Scheffe's test was used for dimensional comparisons. It shows.

Table (11): Scheffe test results for dimensional comparisons of the averages of parents' estimates on the scale of satisfaction with family life attributable to the variable of the economic level

\begin{tabular}{cccccc}
\hline & Economic level & & Low & medium & high \\
\cline { 3 - 6 } Scale & & SMA & 3.72 & 3.84 & 0.18 \\
\hline $\begin{array}{c}\text { Satisfaction with } \\
\text { family life }\end{array}$ & Low & 3.72 & & 0.11 \\
& medium & 3.84 & & $* .63$ \\
& high & 3.90 & & \\
\hline
\end{tabular}

* Statistically significant at the level of significance $(\alpha \leq 0.05)$

Table (11) shows that there is a statistically significant difference at the level of significance $(\alpha \leq 0.05)$ between the mean estimates of parents on the scale of satisfaction with family life between those with a high economic level on the one hand and high on the other hand in favor of the high economic level.

The results indicated that there are no differences in stressful life events and parental tension attributable to the variable of gender, the researchers attribute this result to the difficult psychological, economic and social pressures that members of the Jordanian society, especially parents, suffer from, and the more these pressures on the family, the greater the incidence of disturbances and tension. So, surrender to the negative energy caused by the instability of the psychological state, and the stress to separate the problems and pressures facing parents from their marital life. The decline in family, social, and economic conditions lead to psychological and emotional defects in the character of the parents. In addition, the failure to satisfy psychological needs, negative interactions within the family, the emergence of family problems, the failure provide support and assistance in various situations, the inadequacy of the economic events, the failure to perform the family tasks and meals for each of the parents, and the charged family atmosphere based on the lack of integration in the relationship between the father And the mother, lack of interest in solving family problems, which leads to a feeling of tension and anxiety in parents. The results of this study are consistent with the study of Flouri et al. (Flouri, et al., 2018), and the study of Bani Mustafa et al. (2014), which indicated that there are no differences in the level of stressful life events attributable to the gender variable. The results of this study differ with the Chi \& Xu study (Chi \& Xu, 2018) which indicated that mothers are more stressed than male fathers are.

The results also indicated that differences in the level of satisfaction with family life due to the gender variable in favor of mothers, researchers attribute this result to the fact that family support leads mothers to feel their importance and value in this life, which leads to an increase in the level of satisfaction with family life, as the satisfaction of needs.

Their different essentials are a major component of their quality of life. The presence of a good level of life aspects increases mothers' sense of happiness and contentment with family life, and the ability to achieve their own goals, as their interaction and positive perception of marital life reflected in their level of happiness and their sense of meaning of life, which leads them to reach satisfaction with family life. The results of this study are consistent with the Ziada study (2018), which indicated that there are statistically significant differences in the level of satisfaction with family life according to gender and in favor of females. The results of this study differed with the study of Dradke (2019), which indicated that there are differences between the sexes on the two 
measures of satisfaction with family life in favor of males. In addition, the study of Bani Mustafa and others (2014), which indicated that there were no differences in the level of life satisfaction due to the variable of sex.

The fifth question: What is the percentage of the explained variance that is explained by the stressful life events of parental tension among the study sample members?

To answer this question, a multiple regression analysis was conducted to reveal the extent to which the dimensions of stressful life events contribute to parental stress. Table (8) shows the results of this analysis.

Table (8): Results of a scaled multiple regression analysis of the extent to which stressful life dimensions contribute to predicting parental stress

\begin{tabular}{|c|c|c|c|c|c|}
\hline Dimensions $\backslash$ Form & $\begin{array}{c}\text { Multiple } \\
\text { correlation R }\end{array}$ & Contrast $\mathrm{R}^{2}$ & $\begin{array}{l}\text { Change in } \\
\text { contrast }\end{array}$ & F & $\begin{array}{l}\text { Statistical } \\
\text { significance }\end{array}$ \\
\hline 1 & 0.27 & 0.07 & $\% 9$ & 21.43 & 0.000 \\
\hline 2 & 0.30 & 0.10 & $\% 7$ & 16.27 & 0000 \\
\hline 3 & 0.34 & 0.12 & $\% 4$ & 22.81 & 0000 \\
\hline 4 & 0.35 & 0.13 & $\% 3$ & 20.26 & 0000 \\
\hline 5 & 0.38 & 0.15 & $\% 1$ & 19.94 & 0000 \\
\hline $\begin{array}{l}\text { 1: Predictors (economic ev } \\
\text { 2: Predictors (economic ev } \\
\text { 3: Predictors (economic ev } \\
\text { 4: Predictors (economic ev } \\
\text { 5: Predictors (economic ev }\end{array}$ & $\begin{array}{l}\text { ological events } \\
\text { ological events } \\
\text { ological events } \\
\text { ological events }\end{array}$ & $\begin{array}{l}\text { illy events). } \\
\text { ily events, so } \\
\text { illy events, so }\end{array}$ & $\begin{array}{l}\text { events) } \\
\text { events, healt }\end{array}$ & & \\
\hline
\end{tabular}

Table (8) shows that the value of the explained variance of the five economic, psychological, family, social and health dimensions is (24\%). Economic events contributed an amount (9\%) of the total explained variance in a positive relationship, and psychological events contributed (7\%) From the total explained variance and in a direct relationship, as the family events contributed an amount (4\%) of the total explained variance in a direct relationship, and the social events contributed with (3\%) of the total explained variance in a positive relationship, and the health events finally contributed by an amount (1\%) Of the total variance explained by a direct relationship. Table (9) shows the standard and non-standard weights and the "t" value for the variables predicting parental stress.

Table (9): Standard and non-standard weights and a "t" value for variables predicting parental stress

\begin{tabular}{|c|c|c|c|c|c|c|}
\hline \multirow[t]{2}{*}{ Dimensions $\backslash$ Form } & \multirow[t]{2}{*}{ Predictive variables } & \multicolumn{2}{|c|}{ standard weights } & \multirow{2}{*}{$\begin{array}{c}\text { non- } \\
\text { standard } \\
\text { weights }\end{array}$} & \multirow{2}{*}{$\begin{array}{c}\mathrm{T} " \text { " } \\
\text { value }\end{array}$} & \multirow{2}{*}{$\begin{array}{l}\text { Statistical } \\
\text { significance }\end{array}$} \\
\hline & & B & $\begin{array}{c}\text { Standard } \\
\text { error }\end{array}$ & & & \\
\hline \multirow[t]{6}{*}{5} & $\begin{array}{c}\text { Regression } \\
\text { (constant }\end{array}$ & 2.148 & 0.198 & & 7.485 & 0.000 \\
\hline & Economic events & 0.524 & 0.086 & 0.45 & 6.142 & 0.000 \\
\hline & $\begin{array}{l}\text { Psychological } \\
\text { events }\end{array}$ & 0.219 & 0.087 & 0.32 & 5.836 & 0.003 \\
\hline & Family events & 0.347 & 0.085 & 0.28 & 6.429 & 0.000 \\
\hline & Social events & 0.495 & 0.088 & 0.21 & 8.246 & 0.000 \\
\hline & Health events & 0.276 & 0.084 & 0.19 & 4.158 & 0.002 \\
\hline
\end{tabular}

It is evident from Table (9) that all the predictive variables are function at the level of significance $(\alpha \leq 0.05)$, which indicates that all five dimensions (economic, psychological, family, social, and health) predict parental tension as the standard weights of these variables reached (0.45) for events. Economic, $(0.32)$ for psychological events, (0.28) for family events, $(0.21)$ for social events, and (0.19) for health events.

The results showed that there are differences in the level of stressful life events and parental tension attributable to the variable of the economic level in favor of the low economic level. Anxiety and fear for his future if a hateful sign happened to them. The lower the economic level of the family, the effect of this on the psychological side of the parents, and the incidence of fear and anxiety for the future of children and the provision of basic needs for them. The results of this study are consistent with the study of Chi \& Xu (2018), which indicated that parental stress is associated with low economic status, while higher income they have less stress.

The results also showed that there are differences in the level of satisfaction with family life due to the variable of the economic level in favor of the high economic level, as the researchers attribute this result to the fact that the high material level is important to the level of satisfaction with family life. One of the basic needs and well-being, and thus the emergence of aspects of satisfaction and satisfaction with the life they lead. The results of this study are consistent with the study of Botha et al. (2018), which indicated that higher levels of socioeconomic 
status were associated with increased satisfaction with family life, and with the family tool in terms of family resilience. Moreover, the study of Agate et al. (2009) that higher monthly income are positive predictors of satisfaction with family life.

The sixth question: What is the percentage of the explained variance that is explained by stressful life events with satisfaction with family life among the study sample members?

To answer this question, a graded multiple regression analysis was conducted to reveal the extent to which the dimensions of stressful life events contribute to satisfaction with family life. Table (10) shows the results of this analysis.

Table (10): Results of a graded multiple regression analysis of the extent to which the stressful life dimensions contribute to predicting family life satisfaction

\begin{tabular}{cccccc}
\hline Dimensions $\backslash$ Form & $\begin{array}{c}\text { Multiple } \\
\text { correlation R }\end{array}$ & Contrast R & $\begin{array}{c}\text { Change in } \\
\text { contrast }\end{array}$ & F & $\begin{array}{c}\text { Statistical } \\
\text { significance }\end{array}$ \\
\hline 1 & 0.34 & 0.11 & $\% 10$ & 24.16 & 0.000 \\
2 & 0.31 & 0.14 & $\% 8$ & 21.98 & 0000 \\
3 & 0.29 & 0.15 & $\% 6$ & 23.75 & 0000 \\
4 & 0.26 & 0.17 & $\% 3$ & 20.97 & 0000 \\
5 & 0.24 & 0.18 & $\% 2$ & 19.90 & 0000 \\
\hline 1: Predictors (family events) & & & & \\
2: Predictors (family events, psychological events) & & & \\
3: Predictors (family events, psychological events, health events) & & & \\
4: Predictors (family events, psychological events, health events, social events) \\
5: Predictors (family events, psychological events, health events, social events, economic events) \\
\end{tabular}

Table (10) shows that the value of the explained variance for the five familial, psychological, health, social and economic dimensions is (29\%).

Where family events contributed an amount (10\%) of the total explained variance in a positive relationship, psychological events contributed (8\%) of total explained variance and in a direct relationship, health events contributed $(6 \%)$ of the total explained variance in a direct relationship, social events contributed with a percentage $(3 \%)$ of the total explained variance in a positive relationship, and the economic events finally contributed of (2\%) Of the total explained variance in a direct relationship. Table (11) shows the standard and non-standard weights and the " $t$ " value of the variables predicting satisfaction with family life.

Results indicated that all dimensions of stressful life events predicted negatively parental tension, as the researchers attribute that the economic conditions that individuals go through have a major role in their lives, as the individual's instability in a particular work and the transition from one job to another, accompanied by changes in the psychological and social aspects and lack of financial stability of the family, and making family members, especially parents, live in difficult circumstances that focus on providing the basic requirements of the family, which puts them in a field of pressure and thus the emergence of tension in them on the aspects of personality. Perhaps environmental pressures related to work, pressures on children, and their personal characteristics and requirements; In addition to the personality of the fathers in terms of their tendencies and gender characteristics, they contributed to the emergence of parental tension.

Table (11): Standard and non-standard weights and the " $t$ " value of variables predicting satisfaction with family life

\begin{tabular}{|c|c|c|c|c|c|c|}
\hline \multirow[t]{2}{*}{ Dimensions $\backslash$ Form } & \multirow[t]{2}{*}{ Predictive variables } & \multicolumn{2}{|c|}{ non-standard weights } & \multirow{2}{*}{$\begin{array}{c}\begin{array}{c}\text { Standard } \\
\text { weights }\end{array} \\
\text { Beta }\end{array}$} & \multirow{2}{*}{$\begin{array}{c}\text { T" " } \\
\text { value }\end{array}$} & \multirow{2}{*}{$\begin{array}{l}\text { Statistical } \\
\text { significance }\end{array}$} \\
\hline & & B & $\begin{array}{c}\text { Standard } \\
\text { error }\end{array}$ & & & \\
\hline \multirow[t]{6}{*}{5} & $\begin{array}{l}\text { (Regression } \\
\text { constant) }\end{array}$ & 1.983 & 0.201 & & 6.492 & 0.000 \\
\hline & Family events & 0.438 & 0.091 & -0.43 & 5.146 & 0.000 \\
\hline & $\begin{array}{l}\text { Psychological } \\
\text { events }\end{array}$ & 0.326 & 0.084 & -0.38 & 7.943 & 0.000 \\
\hline & Health events & 0.291 & 0.088 & -0.34 & 7.217 & 0.000 \\
\hline & Social events & 0.389 & 0.087 & -0.29 & 6.245 & 0.000 \\
\hline & Economic events & 0.401 & 0.083 & -0.26 & 5.198 & 0.000 \\
\hline
\end{tabular}

It is evident from Table (11) that all the predictive variables are function at the level of significance ( $\alpha \leq$ 0.05), which indicates that all five dimensions (family, psychological, health, social, and economic) predict satisfaction with family life, as the standard weights of these variables reached (0.43). -) for family events, (--0.38) for psychological events, (--0.34) for health events, (-0.29) for social events, and (--0.26) for economic events. 
The results indicated that all dimensions of stressful life events predicted positively satisfaction with family life, as the researcher attributes this result to mothers having a new child, or obtaining a better job financially, and obtaining some incentives and achievements that improve his monthly income, or owning A home for the family, as these factors may help to achieve positivity among parents and thus obtain a high level of satisfaction with family life. The results of this study are in agreement with the study of Flouri et al. (Flouri, et al., 2018), which indicated that juveniles predict the level of mental health similarly to parents.

\section{Recommendations:}

In light of these results, the researchers recommend the following:

- Work on conducting more studies that link life events with family aspects in different settings, and conducting studies that take other independent variables not included in this study.

- Paying attention to developing satisfaction with family life among members of society in general, because of its effective role in achieving positive mental health and getting rid of psychological tension.

- Increasing interest in conducting special family programs for newlyweds that would develop a sense of contentment and the ability to challenge life's pressures.

- The need to involve children in families in discussing issues related to the family, directing them to how to achieve their goals, guiding them on how to achieve satisfaction with family life in a sound and constructive manner, and providing them with effective methods in facing life's pressures and events.

\section{References}

1. Abd al-Rahman, I. \& Ala al-Din, J. (2011). The effectiveness of a group counseling program in reducing stress and pessimism among mothers of Jordanian children with cancer. Jordan Journal of Educational Sciences, 7 (4): $371-397$.

2. Abidin, R. (1995). Parenting stress index: Professional manual. Odessa, FL: Psychological Assessment Resources, Inc.

3. Abu Mustafa, N.\& Al-Sumairi, N. (2008). The relationship of stressful events to aggressive behavior: a field study on a sample of Al-Aqsa University students. Journal of the Islamic University - Human Studies, 16 (1): 347-410.

4. Agate, J., Zabriskie, R., Agate, S. \& Poff, R. (2009). Family leisure satisfaction and satisfaction with family life. Journal of Leisure Research, 41 (2): 205-223, https://doi.org/10.1080/00222216.2009.11950166.

5. Allam, Z. (2011). Stressful life events, vulnerable to stress and depression among Eritrean high school students. IFE Psychologia: An International Journal, 19(2), 380-393, https://doi.org/10.4314/ifep.v19i2.69583.

6. Al-Layl, M. \& Al-Andijani, A. (2015). Parental concern and its relationship to optimism about the future of gifted children in middle school in the holy city of Makkah. Journal of Special Education, 10: 305-338, https://doi.org/10.12816/0021000.

7. Bandura, A., Caprara, G., Barbaranelli, C., Regalia, C. \&Scabini, E. (2011). Impact of family efficacy beliefs on quality of family functioning and satisfaction with family life. Applied Psychology: An International Review, 60 (3): 421-448, https://doi.org/10.1111/j.1464-0597.2010.00442.x.

8. Bani Mustafa, M., Al-Sharifin, A. \& Tashtoush, R. (2014). Stressful life events and a sense of satisfaction with life and the relationship between them among Yarmouk University students in Jordan. Journal of Al-Quds Open University for Research and Studies, 34 (2): 205-250.

9. Berry, J. \& Jones, W. (1995). The parental stress scale: Initial psychometric evidence. Journal of Social and Personal Relationships, 12 (3): 463 - 472, https://doi.org/10.1177/0265407595123009.

10. Bloom, M. \& Smith, D. (2001). Brief mental health interventions for the family physician. New York: Springer Science.

11. Botha,F., Booysen, F. \& Wouters, E. (2018). Satisfaction with family life in south Africa: The role of socioeconomic status. Journal of Happiness Studies, 19(8): 2339-2372, https://doi.org/10.1007/s10902-017-9929-z.

12. Chi, L. \&Xu,H. (2018). Parenting stress and its associated factors among parents working in hospitality and services industries of Macau. Journal of Tourism \& Hospitality, 7(3): 1-6, https://doi.org/10.4172/2167-0269.1000362.

13. Chukwuorji, J., Nwoke, M. \& Ebere, M. (2017). Stressful life events, family support and successful ageing in the Biafran War generation. Aging \& Mental Health, 21(1): 95-103, https://doi.org/10.1080/13607863.2015.1083946.

14. Dabrowska, A. \& Pisula, E. (2010). Parenting stress and coping styles in mothers and fathers of pre-school children with autism and down syndrome. Journal of Intellectual Disability Research, 54(3): 266-280, https://doi.org/10.1111/j.13652788.2010.01258.x.

15. Daradkeh, S. (2019). The meaning of life and happiness as predictors of satisfaction with family life for a sample of married couples. Journal of Educational and Psychological Sciences, 20(4): 201-232, https://doi.org/10.12785/jeps/200407.

16. Evenson, R. \& Simon, R. (2005). Clarifying the relationship between parenthood and depression. Journal of Health and Social Behavior, 46(4): 341-358, https://doi.org/10.1177/002214650504600403. 
17. Flouri, E., Narayanan, M. \& Naerde, A. (2018). Stressful life events and depressive symptoms in mothers and fathers of young children. Journal of Affective Disorders, 230: 22-27, https://doi.org/10.1016/j.jad.2017.12.098.

18. Glendon, A., Clarke, S. \& Mckenna, E. (2006). Human safety and risk management. New York: Routledge, Taylor \& Francis Group, LLC.

19. Goldenberg, H. \& Goldenberg, I. (2008). Family therapy: An overview. USA: Thomson Books/Cole.

20. Gupta, S. \&Venkatesan, S. (2018). Handbook of research on psychosocial perspectives of human communication disorders. USA: IGI Global.

21. Hajhashemi, K., Caltabiano, N. \& Lovisotto, R. (2015). Stress, affective symptoms and marital satisfaction in parents of children with autism spectrum disorder. Grin Verlag: Open publishing GmbH.

22. Hammen, C. (2005). Stress and depression. Annual Review of Clinical Psychology, 1: 293-319.

23. Hassanzadeh, A., Heidari, Z., Feizi, A., Keshteli, A., Roohafza, H., Afshar, H. \&Adibi, P. (2017). Association of stressful life events with psychological problems: a large-scale community-based study using grouped outcomes latent factor regression with latent predictors. Computational and Mathematical Methods in Medicine, 1(1): 1-12, https://doi.org/10.1155/2018/8020962.

24. Hobson, C., Kamen, J., Szostek, J., Nethercut, C., Tiedmann, J. \& Wojnarowicz, S. (1998). Stressful life events: A revision and update of the social readjustment rating scale. International Journal of Stress Management, 5(1): 1-23.

25. Karademas, E. \& Roussi, P. (2016). Financial strain, dyadic coping, relationship satisfaction, and psychological distress: A dyadic mediation study in Greek couples. Stress \& Health, 33(5): 508-517, https://doi.org/10.1002/smi.2735.

26. Kellermanns, F. \& Hoy, F. (2017). The routledge companion to family business. New York: Routledge, Taylor \& Francis Group, LLC.

27. Lovejoy, M., Graczyk, P., O’Hare, E. \&Neuman, G. (2000). Maternal depression and parenting behavior: A meta-analytic review. Clinical Psychology Review, 20(5): 561-592, https://doi.org/10.1016/s0272-7358(98)00100-7.

28. Luhmann, M., Lucas, R., Eid, M. \& Diener, E. (2013). The prospective effect of life satisfaction on life events. Social Psychological \& Personality Science, 4(1): 39-45, https://doi.org/10.1177/1948550612440105.

29. Malhotra, S, \& Mehta, V. (2008). Role of stressful life events in induction or exacerbation of psoriasis and chronic urticarial. Indian Journal of Dermatology Venereology \& Leprology, 74 (6): 594-599, https://doi.org/10.4103/03786323.45100 .

30. Maurer, F, \& Smith, C. (2013). Community/public health nursing practice: Health for families and population. Missouri: Elsevier Saunders.

31. Mazloum, A. (2008). The level of academic ambition and its relationship to stressful life accidents among university students. Babylon University Journal of the Humanities, 18 (1): 201-232.

32. Mendenhall, A. \& Mount, K. (2011). Parents of children with mental illness: Exploring the caregiver experience and caregiver focused interventions. Families in Society. The Journal of Contemporary Social Services, 92 (2): 183-190, https://doi.org/10.1606/1044-3894.4097.

33. Nadkarni, R. \& Fristad, M. (2012). Stress and support for parents of youth with bipolar disorder. The Israel Journal of Psychiatry \& Related Sciences, 49 (2): 104-110.

34. Nelson, J., O’Brien, M., Blankson, A., Calkins, S. \& Keane, S. (2009). Family stress and parental responses to children’s negative emotions: tests of the spillover, crossover, and compensatory hypotheses. Journal of Family Psychology, 23(5): 671-679, https://doi.org/10.1037/a0015977.

35. Odeh A. (2010). Measurement and evaluation in the teaching process. House of Hope for Publishing and Distribution, Irbid, Jordan.

36. Parke, R. (2002). Fathers and families. In: Bornstein MH, editor. The handbook of parenting: Vol. 3. Being and becoming a parent. 2. Mahwah, New Jersey: Erlbaum.

37. Parkes, A., Sweeting, H, \& Wight, D. (2015). Parenting stress and Parent support among mothers with high and low education. Journal of Family Psychology, 29(6): 907-918, https://doi.org/10.1037/fam0000129.

38. Peterson, G, \& Bush, K. (2013). Handbook of marriage and the family. New York: Springer Science.

39. Poff, R., Zabriskie, R, \& Townsend, J. (2010). Modeling family leisure and related constructs: A national study. Journal of Leisure Research, 42(3): 365-391, https://doi.org/10.1080/00222216.2010.11950210.

40. Pontoppidan, M, Nielsen, T. \& Kristensen, I. (2018). Psychometric properties of the Danish parental stress scale: Rasch analysis in a sample of mothers with infants. PlosOne, 13 (11), 1-20, https://doi.org/10.1371/journal.pone.0205662.

المجلة الدولية للدراسات التربوية والنفسية- المجلد9، العدد3- 2021، ص: 952-967 
41. Rahim, M., Ishak, I., Shafia, S., \&Shafiai, R. (2013). Factors influencing family life satisfaction among parents in Malaysia: The structural equation modeling approach (SEM). Journal of Humanities and Social Science, 17(4): 78-85, https://doi.org/10.9790/0837-1747885.

42. Salerno, J., Yang, S, Nau, D., \& Chai, S. (2011). Social computing, behavioral-cultural modeling and prediction.Heidelberg: Springer- Verlag Berlin.

43. Sauro,J.,\&Lewis.,J.(2012). Quantifying the user experience: practical statistics for user research. Morgan kaufman. $187-$ 262

44. Schnettler, B., Miranda-Zapata, E., Grunert, K., Lobos, G., Denegri, M., Hueche, C. \& Poblete, H. (2017). Life satisfaction of university students in relation to family and food in a developing country. Frontiers in Psychology, 8: 1522-1534, https://doi.org/10.3389/fpsyg.2017.01522.

45. Sori, C. (2006). Engaging children in family therapy: Creative approaches to integrating theoryand research in clinical practice. New York: Routledge, Taylor \& Francis Group, LLC.

46. Valiente, C., Lemery-Chalfant, K. \&Reiser, M. (2007). Pathways to problem behaviors: Chaotic homes, parent and child effortful control, and parenting. Social Development, 16 (2): 249-267, https://doi.org/10.1111/j.1467-9507.2007.00383.x.

47. Widarsson, M., Engström, G., Rosenblad, A., Kerstis, B., Edlund, B. \& Pranee Lundberg, P. (2012). Parental stress in early parenthood among mothers and fathers in Sweden. Scandinavian Journal of Caring Sciences, 27(4): 839-847, https://doi.org/10.1111/j.1471-6712.2012.01088.x.

48. Zabriskie, R. \& Ward, P. (2013). Satisfaction with family life scale. Marriage \& Family Review, 49(5): 446-463, https://doi.org/10.1080/01494929.2013.768321.

49. Ziadeh, A. (2018). The level of satisfaction with family life and self-satisfaction among a sample of Syrian refugees in Jordan. Arab Journal of Science and Research Publishing - Journal of Educational and Psychological Sciences, 6(2): 72-90. 